\title{
Spin Densities in Copper-Nitronyl Nitroxide Complexes*
}

\author{
J.-X. Boucherle, E. Ressouche, and J. Schweizer \\ DRFMC/SPSMS/MDN Centre d'Études Nucléaires de Grenoble, 85X, 38041 Grenoble Cédex, \\ France \\ B. Gillon \\ Laboratoire Léon Brillouin, Centre d'Études Nucléaires de Saclay, 91191 Gif sur Yvette Cédex, France \\ P. Rey \\ DRFMC/SESAM/CC Centre d'Études Nucléaires de Grenoble, 85X, 38041 Grenoble Cédex, France
}

Z. Naturforsch. 48a, 120-122 (1993); received February 7, 1992

The spin density in two copper-nitronyl nitroxide complexes, viz. bis(hexafluoroacetylacetonato)-
(2,4,4,5,5-pentamethyl-1-oxy-imidazoline 3 -oxide)-copper(II) and dichloro-bis(2-phenyl-4,4,5,5-tetra-
methyl-1-oxy-imidazoline 3 -oxide)-copper(II), has been determined by polarised-neutron diffrac-
tion. Spin populations and unpaired electron wave functions have been refined.
Key words: Nitronyl nitroxide free radicals; Copper complexes; Polarised neutron diffraction; Spin
density.

Complexes of nitroxide radicals with metallic ions have attracted much interest in recent years in the area of designing molecular magnets. Several approaches exist, among which one consists in building threedimensional networks of metallic ions linked by nitronyl nitroxide free radicals. These radicals (Fig. 1) are stable and can connect two metallic ions leading to chains through which magnetic interactions propagate. They are characterised by one unpaired electron in a $\pi^{*}$-antibonding orbital built from the $2 \mathrm{p}_{z}$ atomic orbitals of the two $\mathrm{N}$ and the two $\mathrm{O}$ atoms.

In copper complexes, the geometry of the coordination is very critical [1]. When such complexes are axially coordinated, they present a ferromagnetic coupling that can be understood in terms of orthogonality of magnetic orbitals [2]. When they are coordinated in a plane (equatorial coordination), they present antiferromagnetic interactions resulting from the overlapping of half-filled orbitals [2].

Two copper-nitronyl nitroxide compounds, $\mathrm{Cu}(\mathrm{hfac})_{2} \mathrm{Nit}-\mathrm{Me}$ (bis(hexafluoroacetylacetonato)(2,4,4,5,5-pentamethyl-1-oxy-imidazoline 3-oxide)copper(II), CAS reg. no. 106865-84-3) and

* Presented at the Sagamore X Conference on Charge, Spin and Momentum Densities, Konstanz, Fed. Rep. of Germany, September 1-7, 1991.

Reprint requests to Dr. J.-X. Boucherle, DRFMC/SPSMS/ MDM, C.E.N.G., 85X, F-38041 Grenoble Cédex, France.
$\mathrm{CuCl}_{2}(\mathrm{Nit} \varphi)_{2} \quad$ (dichloro-bis(2-phenyl-4,4,5,5-tetramethyl-1-oxy-imidazoline 3-oxide)-copper(II), CAS reg. no. 103816-75-7), belonging to each of the above classes of coordination have been studied. The first one, axially coordinated, is formed by chains ... Nit-Cu-Nit... (Fig. 2), parallel to each other [3, 4]. The second one, with the equatorial coordination, is made of quasi-isolated molecules formed of 3 entities, Nit-Cu-Nit (Fig. 3) [5]. As previously described, $\mathrm{Cu}(\mathrm{hfac})_{2}$ Nit-Me presents a ferromagnetic coupling within the chains, whereas $\mathrm{CuCl}_{2}(\mathrm{Nit} \varphi)_{2}$ presents an antiferromagnetic coupling inside the molecules. In this latter compound, another interaction, an antiferromagnetic coupling between neighbouring molecules, leads to a susceptibility maximum at $T=13 \mathrm{~K}$.

Polarised-neutron experiments have been undertaken on the two compounds. The experimental conditions are summarised in Table 1. In order to analyse

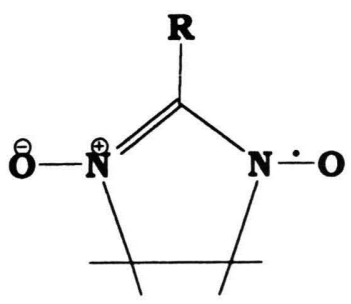

Fig. 1. General formula of nitronyl nitroxides.

0932-0784 / 93 / 0100-0120 \$01.30/0. - Please order a reprint rather than making your own copy. 


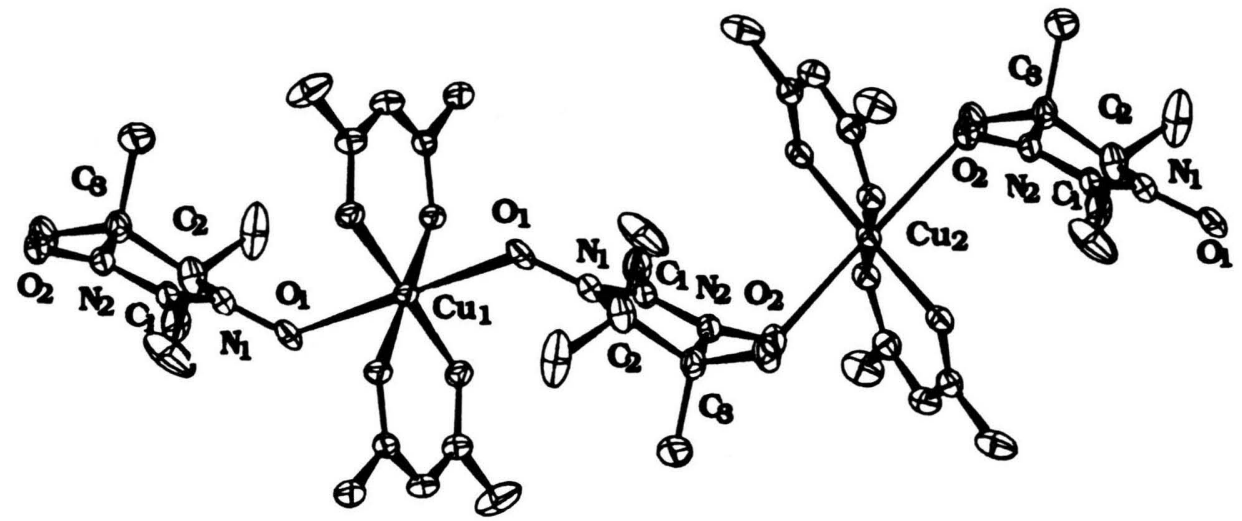

Fig. 2. View of the structure of the complex $\mathrm{Cu}(\mathrm{hfac})_{2} \mathrm{Nit}-\mathrm{Me}[3]$.

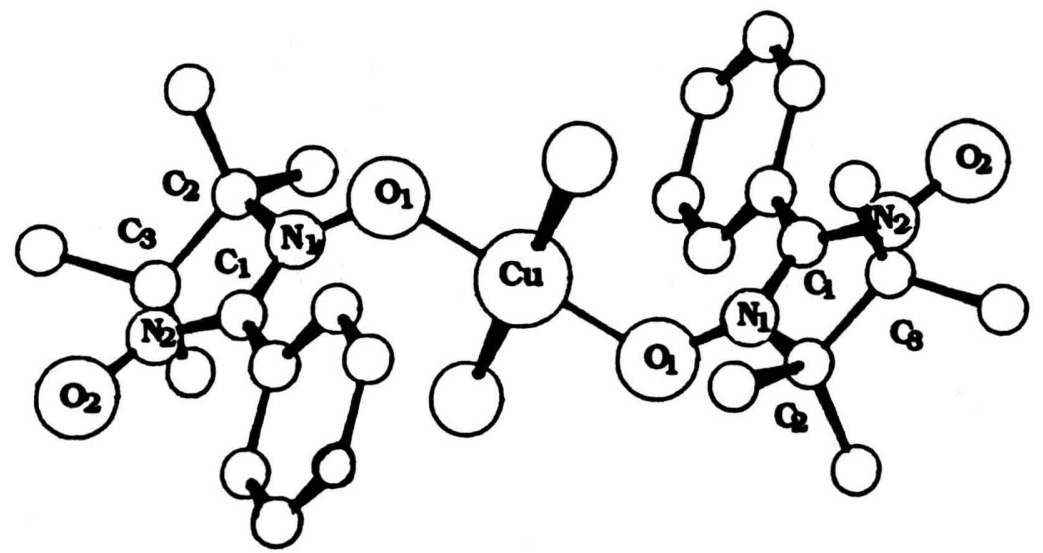

Fig. 3. View of the structure of the complex $\mathrm{CuCl}_{2}(\mathrm{Nit} \varphi)_{2}$ [5].

Table 1. Experimental conditions of the polarised-neutron experiments.

\begin{tabular}{lll}
\hline & $\mathrm{Cu}(\mathrm{hfac})_{2} \mathrm{Nit}^{\mathrm{Me}}$ & $\mathrm{CuCl}_{2}(\mathrm{Nit} \varphi)_{2}$ \\
\hline Spectrometer & $\mathrm{D} 3$ (ILL) & $\mathrm{D} 3$ (ILL) \\
Temperature & $2.5 \mathrm{~K}$ & $13 \mathrm{~K}$ \\
Applied field & $4.6 \mathrm{~T}$ & $4.6 \mathrm{~T}$ \\
Number of observ. & 162 & 227
\end{tabular}

our data, we have refined the unpaired-electron wave functions and the spin populations from the flipping ratios [6]. Results of refinements are presented in Table 2. Figs. 4 and 5 are projections of the spin density along the $\pi^{*}$-direction.

In the first compound, $\mathrm{Cu}$ (hfac) ${ }_{2} \mathrm{Nit}-\mathrm{Me}$, where the coordination is of axial type and where the coupling is weakly ferromagnetic, we observe a deformation of the spin density in the radical. In particular, the two
Table 2. Refined spin populations (magnetic moments in multiples of $\mu_{\mathbf{B}}$ ) from polarised-neutron data.

\begin{tabular}{lllr}
\hline $\mathrm{Cu}(\mathrm{hfac})_{2} \mathrm{Nit}-\mathrm{Me}$ & Populations & $\mathrm{CuCl}_{2}(\mathrm{Nit} \varphi)_{2}$ & Populations \\
\hline $\mathrm{Cu}_{1}$ & $0.858(9)$ & $\mathrm{Cu}$ & $-0.020(2)$ \\
$\mathrm{Cu}_{2}$ & $0.754(8)$ & $\mathrm{N}_{1}$ & $0.017(2)$ \\
$\mathrm{N}_{1}$ & $0.311(8)$ & $\mathrm{N}_{2}$ & $0.018(2)$ \\
$\mathrm{N}_{2}$ & $0.299(8)$ & $\mathrm{O}_{1}$ & $0.000(2)$ \\
$\mathrm{O}_{1}$ & $0.205(7)$ & $\mathrm{O}_{2}$ & $0.019(2)$ \\
$\mathrm{O}_{2}$ & $0.190(10)$ & $\mathrm{C}_{1}$ & $-0.010(2)$ \\
$\mathrm{C}_{1}$ & $-0.100(9)$ & $\mathrm{C}_{2}$ & $-0.003(2)$ \\
$\mathrm{C}_{2}$ & $-0.040(8)$ & $\mathrm{C}_{3}$ & $-0.002(2)$ \\
$\mathrm{C}_{3}$ & $0.011(8)$ & & \\
\hline
\end{tabular}

$\mathrm{O}$ and the two $\mathrm{N}$ atoms do not play an equivalent rôle any more, as has been shown to be the case in nitroxide free radicals. The second compound is more interesting. $\mathrm{CuCl}_{2}(\mathrm{Nit} \varphi)_{2}$, where the coupling is antiferromagnetic, exhibits a dramatic change of the spin den 

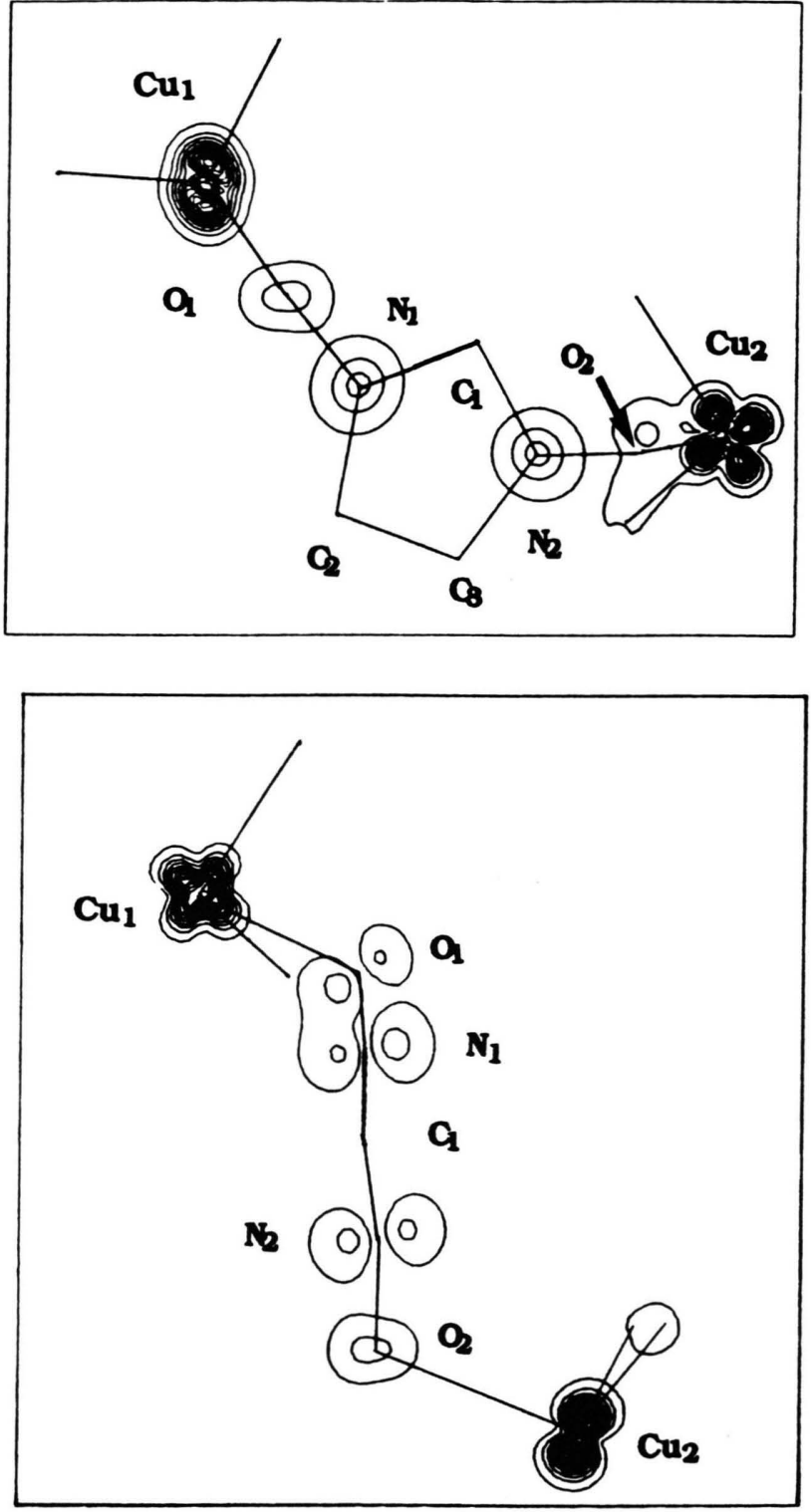

Fig. 4. Spin density projections for the complex $\mathrm{Cu}$ (hfac) 2 Nit-Me, along the $\pi^{*}$ direction (top), onto the $\pi$ plane (bottom).

[1] A. Caneschi, D. Gatteschi, and P. Rey, Prog. Inorg. Chem. 39, 331 (1991).

[2] O. Kahn and B. Briat, J. Chem. Soc. Faraday II, 72 B, 268 and 1441 (1976).

[3] A. Caneschi, D. Gatteschi, J. Laugier, and P. Rey, J. Amer. Chem. Soc. 109, 2191 (1987).
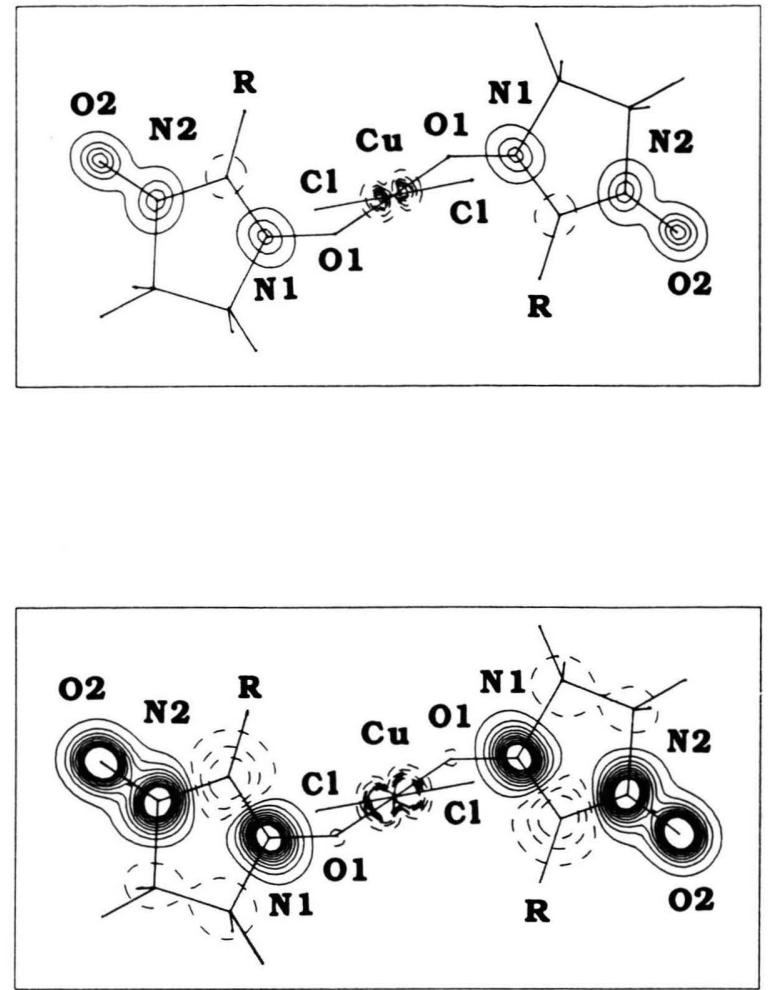

Fig. 5. Spin density projections along the $\pi^{*}$-direction for the complex $\mathrm{CuCl}_{2}(\mathrm{Nit} \varphi)_{2}$.

High level map (top): $\quad 5 \pm n \cdot 10 \mathrm{~m} \mu_{\mathrm{B}} / \AA^{2}$.

Low level map (bottom): $1 \pm n \cdot 2 \mathrm{~m} \mu_{0} / \AA^{2}$.

sity on the radical. This dramatic change can be seen as the fall in density on the bound oxygen together with an increase on the uncoordinated one.

In conclusion, this comparative study clearly shows the strong relation that exists between the binding, the magnetic coupling and the spin density. The stronger the binding in these complexes, the stronger is the magnetic coupling and the stronger is the perturbation of the spin density.

[4] A. Caneschi, D. Gatteschi, A. Grand, J. Laugier, L. Pardi, and P. Rey, Inorg. Chem. 27, 1031 (1988).

[5] J. Laugier, P. Rey, C. Benelli, D. Gatteschi, and C. Zanchini, J. Amer. Chem. Soc. 108, 6931 (1986).

[6] E. Ressouche, Thesis, Univ. Grenoble (1991). 